\title{
Should high-frequency electrosurgery be discouraged during laparoscopic surgery?
}

\author{
Gustavo L. Carvalho ${ }^{1} \cdot$ Eduardo Moreno Paquentin ${ }^{2} \cdot$ Prashanth Rao $^{3}$
}

Received: 18 August 2015/Accepted: 28 August 2015/Published online: 19 October 2015

(C) Springer Science+Business Media New York 2015

This reason for this editorial arose following the publication in Surgical Endoscopy: Biomolecular inflammatory response to surgical energy usage in laparoscopic surgery: results of a randomized study [1]. This RCT is interesting in attempting to quantify the inflammatory response produced by laparoscopic cholecystectomy (LC), conducted with use of electrosurgical dissection (ED) and compared to dissection without use of electrosurgery [1]. Whilst we can no more than agree with the authors on most of their findings, we consider some issues need addressing. In essence by this RCT, the authors conclude that during an LC, the inflammatory response to surgical trauma is significantly greater when ED, on the basis of a sequential increase in IL-6 and TNF-a levels. What is of some concerns to us and other readers of this publication is that the clinical significance, indeed consequence of this rise in cytokines is not addressed by the authors. At our institution, we perform LC with regular use of ED using minilaparoscopic approach, including cauterization of the cystic

Editorial invited by Prof. Dr. Sir Alfred Cuschieri.

Gustavo L. Carvalho

glcmd1@gmail.com

Eduardo Moreno Paquentin

morenomd7@icloud.com

Prashanth Rao

pprao2@mac.com

1 Oswaldo Cruz University Hospital and UNIPECLIN, Faculty of Medical Sciences, University of Pernambuco, Rua Visconde de Jequitinhonha, 1144 SL.910, Recife, PE CEP:51030-020, Brazil

2 Department of General and Laparoscopic Surgery, ABC Medical Center Santa Fe, Mexico City, Mexico

3 Global Hospitals \& Mamata Hospital, Mumbai, India artery. In a series of more than 2000 patients (Table 1) with strict adherence to the well-known principles governing safe ED [2], we have not encountered any CBD injury and not observed any objective adverse effect of ED which delayed recovery, with the vast majority of these patients being discharged within the first $24 \mathrm{~h}$ after their operation, and without any major complaint [3-5].

The development of high-frequency electrocautery by Cushing and Bovie [6], allowed surgeons to dissect and cut living tissues with minimal bleeding and great precision. It's interesting that like Cushing, most of us never really did learn the physics behind one of the most important technical improvements in modern surgery. But undoubtedly Cushing knew well enough that objectively reducing blood loss with precise hemostasis, electrosurgery allowed him to operate more safely in patients with tumors that had been previously deemed inoperable, as well as on those suffering from different kinds of neurosurgical diseases $[6,7]$.

The high temperature and lateral spread of of electric current-particularly when monopolar mode is used—can produce collateral tissue damage.

It is true that monopolar current when applied at $60 \mathrm{~W}$ for $1 \mathrm{~s}$ exhibits a mean critical spread of $3.5 \mathrm{~mm}$; but the spread exceeds $20 \mathrm{~mm}$ when applied for $2 \mathrm{~s}$ or more [8]. Thus, compared to short bursts, a more prolonged continuous current may increase the extent of collateral damage. Electro-thermal damage can result from unrecognized energy transfer within the operative field or from stray currents beyond the operative field (so called 'off screen injuries'). Stray currents can result due to insulation failure, direct coupling or capacitive coupling. The entire surgical team should have a sound knowledge of the biophysics of electrosurgery, the basis of equipment, general tissue effects and be aware of the importance of good surgical 
Table 1 Principles for safe use of electrocautery (EC) in minilaparoscopic cholecystectomy

Electrocautery mandates the use of a return electrode monitor

Use bipolar or monopolar energy with blend mode ( $30 \mathrm{w}$ cut, $25 \mathrm{w}$ coagulation, or less)

Never use a metal clip, if use of EC is intended close to the clipped structure

Short pulses should always be used, never exceeding more than $1 \mathrm{~s}$

To avoid damage, EC must be used at least $10 \mathrm{~mm}$ away from vital structures (pedicle, duodenum, colon, etc.)

Use dissecting forceps to coagulate, if artery diameter is $>2 \mathrm{~mm}-$ Hint: Compare with 3-mm forceps

technique and surgical aptitude [9] Thus, it is of utmost importance that ED should be applied judiciously with a thorough knowledge governing its safe working principles, in order to prevent inadvertent injuries [10]. The safe use of electrosurgery has been extensively addressed in the surgical literature $[5,9,10]$. Electrosurgery by itself should not be blamed; instead the improper deployment of ED for various reasons including inadequate training in its safe deployment accounts for most electrosurgical iatrogenic injuries.

In this context it would have benefited the readers of this RCT, if information had been provided with details, including specific settings for the utilization of ED in the study, especially an indication of the amount of this type of energy applied in every case, and application times of each current burst to enable the determine of the exact relation between ED energy and the rise in cytokine levels observed. Otherwise, in our view, a cause/effect relationship may be difficult to prove. Some concern must be raised by the fact that 2 out 51 (approximately $4 \%$ ) of the patients submitted to $\mathrm{LC}$ with the standard of ED set by the authors, suffered a bile duct injury (BDI). The two injured patients were withdrawn from the statistical analysis, but these events represent a major concern regarding the experience with ED during LC by the surgeons involved, since incidence of BDI generally reported in the literature is much less frequent $(0.3-0.7 \%[10,11])$. Four per cent of BDI is approximately 10 times more than the expected rate for this serious complication of LC in the USA. The possibility has to be considered that excess ED energy might have contributed to the observed in the inflammatory cytokine response reported in this RCT.

The appreciation of current density, as distinct from current intensity, is possibly the most important component which requires consideration in view of its impact on safely practice electrosurgery. The amount of current flowing through across sectional area is referred to as "current density' and equals current intensity (CI) in amperes divided by the contact area in $\mathrm{mm}^{2}(\mathrm{CD}=\mathrm{CI} / \mathrm{Area})$. It explains why a hook can transmit more precisely targeted high-frequency electrical current than a spatula or a large tip forceps. Consequently a thinner instrument should be more precise at delivering the same amount of energy in a restricted area, also ensuring a smaller amount of tissue affected by the electrocautery at any given time. Is it possible that a more judicious use of electrosurgery could have limited rise in cytokine levels and avoided the CBD injuries as well. Based on our experience, a more rational use of electrosurgery, using minilaparoscopic techniques, can prevent damage to the CBD. Since it is already well known that energy depth effect and current density are inversely proportional to the contact area of the instrument tip used to cauterize the tissue, and also considering that the area of the instrument tip is proportional to its diameter, we can easily understand that small changes in instrument tip diameter can produce exponential variations in current density, favouring a safer use by the more delicate miniinstruments, because lower generator cautery are needed than those used in standard laparoscopy.

It is not justifiable to conclude that electrosurgery is dangerous [11, 12], and simply abandon what is probably, after anaesthesia, one of the greatest turning points of modern surgery. Newer forms of electrosurgery like active electrode monitoring systems, tissue response generators, and advanced vessel sealing systems appear to further improve the safety of electrosurgery, indicating that our efforts should be not to demonize electrosurgery, but rather promote its conscious and judicious use, always seeking to advance the technologies used in surgery to achieve our main objective: excellent clinical outcome and patients safety. [13].

Finally, we cannot imagine operating in a surgical environment without microprocessor-controlled electrosurgery and other advanced vessel sealing technologies, which facilitate the performance and increase the safety of complex procedures, provided the technology is used properly. As Herodotus had said: 'The only good is knowledge, and the only evil is ignorance'.

\section{Compliance with ethical standards}

Disclosures The main author (Carvalho) declares to have a possible conflict of interest. He is a consultant, without financial interest, for Karl Storz for the development of the new minilaparoscopic low friction trocars. The other authors (Moreno and Rao) have no relevant disclosures to this article. 


\section{References}

1. Agarwal BB, Nanavati JD, Agarwal N, Sharma N, Agarwal KA, Manish K, Saluja S, Agarwal S (2015) Biomolecular inflammatory response to surgical energy usage in laparoscopic surgery: results of a randomized study. Surg Endosc. doi:10.1007/s00464015-4408-2

2. Strasberg SM, Brunt LM (2010) Rationale and use of the critical view of safety in laparoscopic cholecystectomy. J Am Coll Surg 211:132-138

3. Carvalho GL, Silva FW, Silva JS, de Albuquerque PP, Coelho Rde M, Vilaça TG, Lacerda CM (2009) Needlescopic clipless cholecystectomy as an efficient, safe, and cost-effective alternative with diminutive scars: the first 1000 cases. Surg Laparosc Endosc Percutan Tech 19:368-372

4. Swanstrom LL (2011) "Clipless" cholecystectomy: evolution marches on, even for lap chole. World J Surg 35:824-825

5. Pucher PH, Brunt LM, Fanelli RD, Asbun HJ, Aggarwal R (2015) SAGES expert Delphi consensus: critical factors for safe surgical practice in laparoscopic cholecystectomy. Surg Endosc. doi:10. 1007/s00464-015-4079-z

6. Bovie WT, Cushing H (1928) Electrosurgery as an aid to the removal of intracranial tumors with a preliminary note on a new surgical-current generator. Surg Gynecol Obstet 47:751-784
7. Voorhees JR, Cohen-Gadol AA, Laws ER, Spencer DD (2005) Battling blood loss in neurosurgery: Harvey Cushing's embrace of electrosurgery. J Neurosurg 102:745-752

8. Hefermehl LJ, Largo RA, Hermanns T, Poyet C, Sulser T, Eberli D (2014) Lateral temperature spread of monopolar, bipolar and ultrasonic instruments for robot-assisted laparoscopic surgery. BJU Int 114:245-252

9. Wu MP, Ou CS, Chen SL, Yen EY, Rowbotham R (2000) Complications and recommended practices for electrosurgery in laparoscopy. Am J Surg 179:67-73

10. Madani A, Jones DB, Fuchshuber P, Robinson TN, Feldman LS (2014) Fundamental use of surgical energy TM (FUSE): a curriculum on surgical energy-based devices. Surg Endosc 28:2509-2512

11. Nuzzo G, Giuliante F, Giovannini I, Ardito F, D'Acapito F, Vellone M, Murazio M, Capelli G (2005) Bile duct injury during laparoscopic cholecystectomy: results of an Italian national survey on 56591 cholecystectomies. Arch Surg 140:986-992

12. Waage A, Nilsson M (2006) Iatrogenic bile duct injury: a population-based study of 152.776 cholecystectomies in the Swedish inpatient registry. Arch Surg 141:1207-1213

13. Alkatout I, Schollmeyer T, Hawaldar NA, Sharma N, Mettler L (2012) Principles and safety measures of electrosurgery in laparoscopy. JSLS 16:130-139 